\title{
A teoria dos jogos e a mediação da informação: uma proposta de contribuição estratégica para organizações
}

\author{
Heloá Cristina Camargo de Oliveira \\ Universidad de Salamanca - USAL, España \\ Juliete Susan Ferreira de Souza \\ Universidade Metodista de Piracicaba - UNIMEP, Brasil
}

Marta Lígia Pomim Valentim

Oswaldo Francisco de Almeida Júnior

Universidade Estadual Paulista "Júlio de Mesquita Filho" - Unesp, Brasil

REVIEW

\begin{abstract}
Resumo
Objetivo. Objetiva-se discutir o papel que a mediação da informação pode ter no contexto da Teoria dos Jogos, cujo enfoque refere-se ao conceito de coopetição. Apresenta-se alguns aspectos que podem ser pertinentes para as organizações se adequarem à realidade do mercado atual, enfocando a mediação da informação na perspectiva da Teoria dos Jogos.

Método. Se apresenta um resgate teórico da Teoria dos Jogos no que tange ao compartilhamento da informação e do conhecimento, e da mediação e apropriação da informação.

Resultados. Após os resgastes teóricos foi possível abordar a aplicabilidade da Teoria dos Jogos no âmbito da mediação da informação e da apropriação da informação, no intuito de demonstrar os possíveis benefícios dessa interlocução. Conclui-se que a mediação pode não apenas ser utilizada em conjunto à Teoria dos Jogos, mas também contribuir significativamente para que esta ocorra de maneira plena e proveitosa para as partes envolvidas.
\end{abstract}

Palavras-chave

Ambientes organizacionais; Apropriação da informação; Mediação da Informação; Teoria dos Jogos

Games Theory and Mediation of Information: a proposal of strategic contribution to organizations

\begin{abstract}
Objective. The purpose is to discuss the role that mediation of information can have in the context of Game Theory, which focuses refers to the concept of coopetition. It presents some aspects that can be pertinent for organizations to suit the reality of the current market, focusing on the mediation of information from the perspective of Game Theory.

Method. It presents a theoretical rescue of game theory with regard to sharing of information and knowledge, and of the mediation and appropriation of information.

Results. After the theoretical reviews, it was possible to approach the applicability of Game Theory in the context of mediation of information and information appropriation, in order to demonstrate the potential benefits of this union. It is concluded that mediation can not only be used in conjunction with the Theory of Games, but also significantly contribute to your application in a full and beneficial way for the parties involved.
\end{abstract}

Keywords

Game Theory; Information appropriation; Mediation of information; Organizational environments 


\section{Introdução}

Apresenta-se algumas reflexões acerca da complexidade que permeiam o ambiente em que as organizações contemporâneas estão inseridas e a influência que esta exerce no processo decisório empresarial, bem como na geração de diferenciais competitivos.

O cenário econômico contemporâneo impõe uma relevante mudança de pensamento, uma vez que não se pode mais perceber os fenômenos desse contexto isoladamente e, assim, é essencial que se desenvolva uma visão holística, visando a tomada de decisão, a geração de inovação e o estabelecimento de estratégias de ação de curto, médio e longo prazo.

Nessa perspectiva, se evidencia a importância do compartilhamento de informação e conhecimento entre os sujeitos organizacionais, como subsídio para a geração de inovação de processos, produtos e serviços.

Compreender esse cenário torna-se importante devido as profundas inconstâncias e instabilidades que têm permeado e influenciado todos os segmentos da sociedade. O transpor do reducionismo para a complexidade é uma atitude necessária, uma vez que a visão cartesiana é substituída por uma visão mais ampliada, compreendendo que os fenômenos deste mundo são inter-relacionadas, e que o homem é modificador da sua própria realidade.

No final do Século XX, surge o 'paradigma da complexidade' em contraponto ao 'paradigma da simplificação', que ocorre por causa da incapacidade deste último realizar a conjunção do uno e do múltiplo, propiciando assim a inserção da Teoria da Complexidade no contexto contemporâneo (MORIN, 2007). Segundo Morin (2007, p. 5) a complexidade pode ser compreendida como

[...] um tecido de constituintes heterogêneas inseparavelmente associadas: ela coloca o paradoxo do uno e do múltiplo. Além disso, a complexidade é efetivamente o tecido de acontecimentos, ações, interações, retroações, determinações, acasos, que constituem nosso mundo fenomênico [...] mostra-se que a complexidade se apresenta com os traços inquietantes do emaranhado, do inextricável, da desordem, da ambiguidade, da incerteza. Por isso o conhecimento necessita ordenar os fenômenos rechaçando a desordem, afastar o incerto, isto é, selecionar os elementos da ordem e da certeza, precisar, clarificar, distinguir, hierarquizar.

A complexidade traz consigo a exigência de um pensamento mais ampliado acerca dos fenômenos e do meio no qual as organizações estão inseridas. Assim, tornam-se capazes de reconhecer os fatores determinantes que impactam o negócio organizacional, modificando suas ações em prol de seu desenvolvimento.

Morin (2007, p. 35) explica que a complexidade tem relação com o acaso e "[...] diz respeito a sistemas semialeatórios, cuja ordem é inseparável dos acasos que os concernem. A complexidade é, portanto, uma mistura de ordem e de desordem". Dessa maneira, as organizações contemporâneas imersas nessa dualidade são mais complexas, visto que há uma gama de variáveis envolvidas que, por sua vez, influenciam diretamente nas decisões e na geração de diferenciais competitivos (LACOMBE e HEILBORN, 2008).

Nesse contexto, permeado por diversos desafios e incertezas da contemporaneidade, bem como da evolução das Tecnologias de Informação e Comunicação (TIC), apresenta-se alguns aspectos que podem ser pertinentes para as organizações se adequarem à realidade do mercado atual, enfocando a mediação da informação na perspectiva da Teoria dos Jogos. Para tanto, se apresenta um resgate teórico da Teoria dos Jogos no que tange ao compartilhamento da informação e do conhecimento. Posteriormente, a mediação da informação e a apropriação da informação são debatidas a luz da literatura. Por fim, será abordada a aplicabilidade da Teoria dos Jogos no âmbito da mediação da informação e da apropriação da informação, no intuito de demonstrar os possíveis benefícios dessa união. 


\section{Teoria dos jogos e o compartilhamento da informação e do conhecimento}

O ambiente em que as organizações atuam é extremamente competitivo, influindo na maneira com que valorizam as informações e os conhecimentos gerados em seus ambientes. Tal situação impulsiona e instiga comportamentos voltados a criação, compartilhamento e uso desses elementos, visando maximizar resultados.

O compartilhamento de informação e conhecimento pode ocorrer quando há uma cultura organizacional positiva em relação a ele, ou seja, os valores, as crenças, os ritos e os mitos organizacionais podem contribuir significativamente para proporcionar um ambiente de compartilhamento (ANGELONI e GROTTO, 2009). Davenport e Prusak (1998b, tradução nossa) explicam que o ato de compartilhar ocorre, muitas vezes, de modo involuntário, pois o contexto em que os sujeitos organizacionais estão inseridos pode provocar situações em que a troca naturalmente ocorra.

Evidencia-se, assim, que o conhecimento está presente no ambiente organizacional e é dependente dos sujeitos organizacionais para que ocorra seu compartilhamento. Ipe (2003) afirma que compartilhar conhecimento é basicamente o ato de tornar uma parte [o que for consciente] do conhecimento de um sujeito cognoscente disponível a outro que dele necessite.

Conforme mencionado anteriormente, compartilhar conhecimento não é uma atividade simples, pois depende de vários aspectos, interesse e circunstâncias que podem influir positivamente ou negativamente no ato de compartilhar. Nessa perspectiva, Ipe (2003) identificou os principais fatores que influenciam o compartilhamento de conhecimento entre sujeitos organizacionais: natureza do conhecimento, motivação para compartilhar, oportunidades para compartilhar e cultura do próprio ambiente de trabalho. Além dos mencionados, vale ressaltar que um dos fatores determinantes para que ocorra o compartilhamento se refere aos interesses em compartilhar, seja no âmbito organizacional, seja no âmbito individual.

O primeiro fator influenciador diz respeito a "natureza do conhecimento", que é classificada em dois sentidos: o primeiro centra-se na natureza tácita e explícita do conhecimento, o segundo centra-se no valor atribuído ao conhecimento que, neste caso, é destacado por lpe (2003) como os aspectos comercial e monetário podendo, entretanto, revelar outros como, por exemplo, segurança, produtividade, inovação e qualidade. Em relação ao fator motivacional, Ipe (2003) destaca os sentimentos, as percepções e as relações que, de alguma maneira, podem inibir ou motivar o compartilhamento de conhecimento. As pessoas não compartilham conhecimento sem haver uma motivação pessoal e, normalmente, não o fazem sem saber o que podem ganhar ou perder com isso. No entanto, Stenmark (2000; 2001) afirma que esse fator pode ser amenizado, se a organização desenvolver condições apropriadas para o compartilhamento [cultura, comunicação, infraestrutura etc.], isto é, reconhecer os sujeitos organizacionais que a praticam de modo efetivo. Valentim $(2003$, p. 1) explica que a

[...] cultura organizacional que favoreça o comportamento voltado a gestão do conhecimento, não é fácil, primeiramente, porque as pessoas acreditam que compartilhar conhecimento, significa perder a propriedade intelectual da ideia, dos métodos, dos processos etc., pensados por elas. Num segundo momento, porque as pessoas acreditam que compartilhar conhecimento, significa perder o poder frente às outras pessoas da organização, uma vez que não será o único a pensar sobre aquela possibilidade ou cenário.

Os fatores motivacionais que influenciam o compartilhamento de conhecimento entre os sujeitos organizacionais podem ser divididos, segundo Ipe (2003), em internos e externos. Os fatores internos incluem sentimentos de poder, ligados ao reconhecimento e à reciprocidade que resultam do compartilhamento. Este fator está vinculado à ideia de que "conhecimento é poder", e o sentimento de poder pode dificultar o compartilhamento. Os fatores externos incluem o relacionamento entre diferentes sujeitos organizacionais para haver o compartilhamento, evidenciando que exista confiança entre as partes ou que haja recompensa organizacional. Entretanto, se o indivíduo tem consciência de que o conhecimento lhe confere importância, a tendência é acumular conhecimento e não compartilhar. 
Em relação à reciprocidade existente no compartilhamento, Dyer e Nobeoka (2000) explicam que esta pode se apresentar de duas maneiras: a) direta - que ocorre quando dois indivíduos exercem ao mesmo tempo os papeis de emissores e receptores de informações; e b) indireta - que ocorre quando um terceiro indivíduo contribui sem a expectativa de receber algo em troca. Em relação ao terceiro indivíduo, estes autores destacam que, enquanto ele não tiver a certeza de que receberá uma compensação direta em troca da informação compartilhada, tenderá a zelar pelas informações que detém para posterior compartilhamento.

Ipe (2003) também evidencia a cultura organizacional como um fator preponderante para o compartilhamento de conhecimento, visto que muitos fatores que possibilitam o compartilhamento são influenciados pela cultura e subculturas existentes na organização. A cultura organizacional é uma das maiores barreiras para a construção, o compartilhamento e o uso efetivo de conhecimento.

Desse modo, o compartilhamento de conhecimento entre sujeitos organizacionais pode propiciar comportamento cooperativo e competitivo, denominado de 'coopetição', isto é, ao mesmo tempo em que os sujeitos organizacionais cooperam também competem entre si. Essa situação dual, faz parte da complexidade organizacional contemporânea, e agrega valor propiciando percepções mais amplas sobre um problema, desenvolvendo a criatividade e a aprendizagem, cujos resultados podem gerar inovação ou diferenciais competitivos para a organização.

As organizações que atuam em mercados competitivos, necessitam agir estrategicamente e estabelecerem relacionamentos cooperativos com outras organizações, no intuito de desenvolver conhecimentos e experiências, como subsídio para a tomada de decisão e para a definição de estratégias de ação. Dessa maneira, os sujeitos organizacionais, precisam estar preparados para compartilhar informações, conhecimentos e experiências com outros agentes.

Pereira e Fonseca (2009) descrevem que as inter-relações entre organizações necessitam, a priori, que ambas tenham um objetivo em comum que, por sua vez, só poderá ser alcançado mediante a combinação de esforços. Tal fato evidencia que as organizações e seus sujeitos organizacionais não estão isolados, ou seja, fazem parte de um contexto cujas interconexões são reais. As interações internas e externas que ocorrem no sistema social impõem uma mudança de comportamento, visando a própria sobrevivência, ou seja, é importante criar parcerias que as fortaleçam frente aos mercados incertos em que atuam.

Nessa perspectiva, destaca-se a importância de criar, compartilhar, apropriar e usar informações, conhecimentos e aprendizagens adquiridos por meio das parcerias estabelecidas, visando o crescimento, o aperfeiçoamento e o fortalecimento das organizações que estabelecem as parcerias entre si (PEREIRA e FONSECA, 2009). Assim, na medida em que os sujeitos organizacionais [jogadores] decidem compartilhar informação e conhecimento, criam uma dinâmica para a aprendizagem organizacional em função de objetivos comuns, propiciando um melhor contexto para ambos os jogadores.

A Teoria dos Jogos, segundo Fiani (2006), procura analisar as situações de conflito e de colaboração que ocorrem entre os jogadores, cujo resultado é dependente das ações de outros tomadores de decisão que, também, estão inseridos no jogo estratégico. Assim, ela compreende o sujeito organizacional [jogador] como aquele que consegue modificar a estratégia de um jogo, mediante as informações e conhecimentos que possui e adquiriu ao longo de sua vivência organizacional, enfocando que é por meio das interações estratégicas entre os jogadores que, as decisões se tornam mais precisas, justamente a partir da compreensão ampla da situação em que estão envolvidos (VITORINO FILHO, SACOMANO NETO e SPERS, 2009).

Nesse sentido, a Teoria dos Jogos contribui para uma melhor compreensão dos tipos de comportamentos dos sujeitos organizacionais, principalmente daqueles que tomam decisões constantemente, cujos resultados positivos são imprescindíveis, visto que as organizações precisam criar alianças estratégicas para obter benefícios individuais e coletivos. Fiani (2006) destaca, também, que ela busca analisar as situações que envolvem conflito de interesses, com o intuito de indicar as opções mais adequadas que, sob determinadas condições, conduzirão ao objetivo desejado.

Observa-se uma vantagem da aplicação dessa teoria no contexto organizacional, uma vez que é necessário considerar aspectos que envolvem a percepção dos concorrentes, bem como de outros agentes que influenciam 
direta e/ou indiretamente a organização, pois podem auxiliar na obtenção dos resultados esperados, por meio do ‘jogo' competitivo (VITORINO FILHO, SACOMANO NETO e SPERS, 2009).

Os economistas caracterizam um jogo como um conjunto de regras que descrevem a realidade, definindo os agentes econômicos [jogadores], as possíveis ações [estratégias] dos agentes econômicos e um conjunto de informações que orientam os agentes nas decisões racionais e maximizadoras de resultados (SAUAIA e KALLÁS, 2007). Os mesmos autores explicam que um jogo se subdivide em dois segmentos principais: jogos cooperativos e não cooperativos:

Nos cooperativos, os participantes desejam maximizar o resultado da coalizão e para isso colaboram uns com os outros. Nos não cooperativos, a unidade de análise é o indivíduo que se preocupa em maximizar seus próprios resultados, dentro das regras do jogo, qualquer que seja o resultado coletivo. Na prática a cooperação ficaria bastante facilitada, se proporcionasse o melhor resultado individual e também coletivo (SAUAIA e KALLÁS, 2007, p. 82-83).

$\mathrm{Na}$ Teoria dos Jogos evidencia-se um movimento, por parte dos sujeitos organizacionais, de cooperação, compartilhamento e negociação, desde que essas ações proporcionem bons resultados em âmbito individual e coletivo e, assim, ameniza os conflitos e a competitividade exacerbada, uma vez que por meio da inter-relação entre os sujeitos organizacionais ocorre uma maior comunicação, possibilitando a construção de conhecimento individual e coletivo. Dessa maneira, a cooperação entre jogadores pode propiciar resultados mais adequados para os sujeitos envolvidos (COSTA e BOTTURA, 2006).

Na medida em que o conhecimento é compartilhado entre os sujeitos organizacionais [jogadores], cria-se um ambiente de aprendizagem e, esse contexto, os ajudam a realizar as atividades e tarefas com mais precisão. $O$ compartilhamento de informação e conhecimento não só facilita a interação, mas também contribui para o estabelecimento de confiança entre os sujeitos organizacionais e outros agentes, de modo que se sintam seguros para colaborarem uns com os outros. Além disso, contribui para que o processo não seja fragmentado, isolado, bem como realizado de maneira individual, o que prejudicaria a dinâmica requerida para atuar em um mercado internacionalizado.

Em decorrência disso, as organizações criam alianças estratégicas para atuar no mercado globalizado, desenvolvendo competências e habilidades a partir das parcerias estabelecidas. Contractor e Lorange (2002) definem aliança como sendo, qualquer cooperação entre organizações que desenvolvam algum tipo de relação comercial, seja no curto, médio ou longo prazo.

Casarotto Filho e Pires (2001) explicam que a cooperação é uma alternativa para que a organização desenvolva um bom nível de competitividade, o suficiente para fazer frente às exigências do mercado, pois atuando de maneira individualizada, dificilmente seria possível. As formas organizacionais cooperativas são estruturas que privilegiam as relações de parcerias sem, no entanto, eliminar a competição e os conflitos.

Nessa perspectiva, os níveis de cooperação tendem a ocorrer em situações em que os jogadores são mais seguros e menos gananciosos, cujos ganhos são coletivos. Desse modo, a escolha de um sujeito organizacional está entre o benefício individual ou coletivo, algo que pode ser igualmente positivo para todos os participantes ou pode ser positivo apenas para um dos jogadores, prejudicando os demais (WINCKLER e MOLINARI, 2011). Assim, competir ou cooperar é um dilema da contemporaneidade, estudado por administradores, economistas, matemáticos e cientistas sociais (SAUAIA e KALLÁS, 2007). Nesse sentido, surge o termo 'coopetição', utilizado para designar uma estratégia que integra: "[...] simultaneamente características de cooperação e competição entre um conjunto de organizações, com o objetivo de aumentar o tamanho de mercado (cooperação), sem deixar de disputar participação maior de mercado (competição)" (ZAMPESE e ZILBER, 2011, p. 2).

Nalebuff e Brandenburguer (1996) evidenciam que a 'coopetição' ocorre quando concorrentes são aliados em busca de sinergias que proporcionem diferenciais competitivos e, ao mesmo tempo, concorrem por uma participação maior no mercado em que atuam. As sinergias são resultantes da combinação de recursos e capacidades complementares, propiciando que as organizações tomem decisões mais precisas e eficientes. 
A inter-relação entre as organizações enriquecem e estimulam o processo decisório, porque diversifica e amplia a análise das alternativas e das possíveis consequências, tornando as decisões mais criativas, bem como menos sujeitas a erros. O maior benefício da coopetição é a aprendizagem que pode proporcionar, tornando os sujeitos organizacionais conscientes e capacitados para realizarem futuros ciclos de decisão-ação e engendrando um compromisso efetivo em relação às decisões compartilhadas, fator que os motiva para o alcance dos propósitos desejados.

\section{Mediação da informação}

Historicamente, a existência da mediação "[...] remonta aos idos de 3000 a.C., na Grécia, bem como no Egito, Kheta, Assíria e Babilônia, nos casos entre as Cidades-Estados" (CACHAPUZ, 2003, p. 24 apud SPENGLER, 2010 , p. 17), sendo que sua técnica "[...] se encontra como uma das primeiras formas hábeis de resolver os conflitos, muito antes do surgimento do Estado como um ente politicamente organizado e monopolizador da tutela jurisdicional" (SPENGLER, 2010, p. 17).

O termo mediação pode ser associado a conceitos como conciliação, intercessão, interposição, ligação, interação etc., dependendo do contexto ao qual está relacionado. Áreas como Comunicação, Educação, Filosofia, Direito, Ciência da Informação $(\mathrm{Cl})$, entre outras, usam o termo para enfocar diferentes relações.

Independente do termo ou ideia que exprima sua intenção, a mediação assume uma relação tríplice, na qual se observa a existência de um sujeito [que pode ser o emissor ou o receptor do ato de mediar], um problema/exigência/necessidade/conflito/desejo [dependendo do contexto envolvido] que, por sua vez, estão aliados a um terceiro elemento [o mediador propriamente dito].

Embora tal estrutura tríplice seja recorrente na mediação, ela não se mantém fixa [nem em conceitos nem em sujeitos], e isso resulta em uma variação de termos que dizem respeito a sua significação. No caso da $\mathrm{Cl}$ não é diferente, conforme explica Bortolin (2010) que, após analisar tecnicamente os textos publicados na área de $\mathrm{Cl}$, sobre diferentes abordagens da mediação, é possível identificar que existem

[...] enfoques diferenciados, pois têm concepções diferentes da mediação, sendo ela: processo discursivo, antecipação de desejos, diálogo e interação comunicacional, fluxo de eventos, possibilidade de acesso à informação, solução de conflitos, dispositivo ou instrumento de construção de conhecimento e espaço de aprendizagem, entre outras (BORTOLIN, 2010, p. 119).

Evidencia-se duas abordagens ou enfoques principais sobre a mediação da informação no âmbito da $\mathrm{Cl}$ : a primeira apresenta a mediação como ponte, a segunda como ação. No primeiro caso, a mediação mantém uma posição estática, possibilitando o 'transporte' da informação de um lado para o outro do processo de mediação, estabelecendo assim a ligação entre as extremidades. A partir dessa ideia, pode-se destacar o seguinte exemplo: "O papel do bibliotecário no processo de transferência da informação representa a ponte entre a informação e a pessoa que dela necessita, para tanto, é preciso que ele saiba adquirir, tratar, avaliar e disseminar os muitos suportes informacionais existentes" (MAIA et al., 2011, p. 3, grifo nosso).

$\mathrm{Na}$ demonstrada intenção de expor a necessidade de se adquirir competências e habilidades em relação aos diferentes suportes informacionais, os autores supracitados evidenciam que há a possibilidade de 'transferência de informação', justificando, o uso da metáfora de ponte entre os extremos 'informação-pessoa'. Almeida Júnior (2009, p. 92) esclarece que essa posição se mostra estática, por partir da concepção de que a ponte "[...] leva alguma coisa de um ponto a outro ponto, sendo estes predeterminados e fixos, e sem interferir no trajeto, no modo de caminhar e no final do percurso" e, portanto, não é apropriada.

Na segunda abordagem, a mediação se constitui na ação exercida em um ambiente complexo, cujas nuances envolvem a preocupação com o contexto mediado e com a apropriação da informação pelo sujeito. Pauta-se na natureza humana e no processo cognitivo que, por sua vez, se demonstram passíveis de infinitas variáveis durante seu desenvolvimento, evidenciando sua ancoragem na autonomia do receptor enquanto sujeito inserido em um contexto histórico-social (ALMEIDA JÚNIOR, 2009).

O contexto histórico-social envolve fatores como mídia, cultura e educação etc., compondo um universo informacional único, uma vez que cada indivíduo se relaciona com tais formas, com peculiaridades e 
intensidades distintas. Embora esse relacionamento seja fortemente individual, ele não se desprende da sociedade, pois mesmo se isolando fisicamente, não há indivíduo realmente isolado, visto que leva consigo a memória social, conforme destaca Halbwachs (1990, p. 42): "[...] ele esteve sozinho apenas em aparência, pois, mesmo nesse intervalo, seus pensamentos e seus atos se explicam por sua natureza de ser social e porque ele não deixou sequer por um instante de estar encerrado em alguma sociedade".

A memória é o componente-base da construção do universo informacional, que se encontra presente na mente de cada indivíduo de modo único, cuja relação entre o sujeito e o mundo produz conhecimento que, por sua vez, produz a memória. O mediador da informação que objetiva compartilhar informações deve, obrigatoriamente, se aproximar do universo informacional que visa mediar (Figura 1).

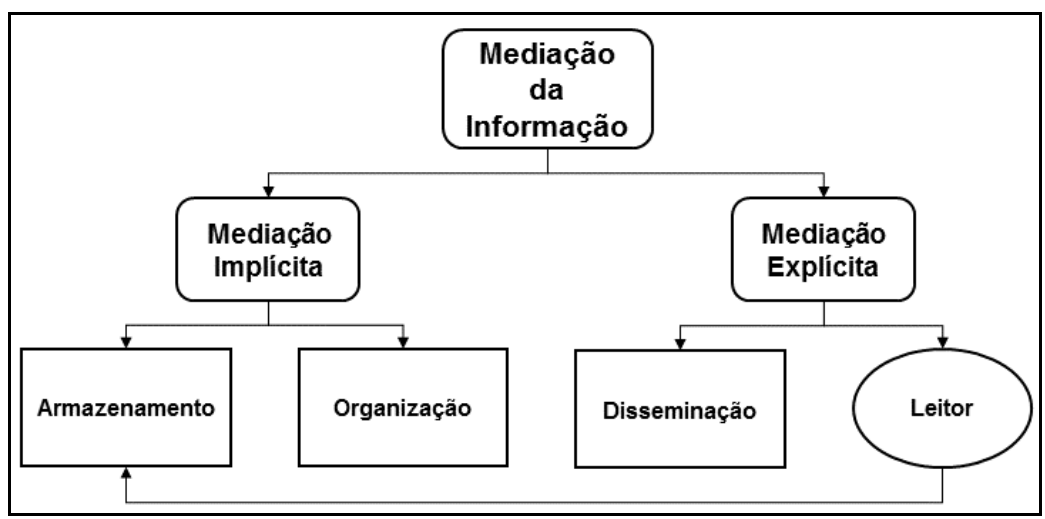

Figura 1. Mediação da informação explícita e implícita - Adaptado de Almeida Júnior (2013)

Observa-se na Figura 1 que a mediação da informação pode ocorrer explícita ou implicitamente, isto é, com ou sem o contato direito com o leitor [sendo esse o 'solicitante' da informação]. A mediação implícita, ou indireta, exige que o mediador possua proatividade, ou seja, procure diferentes maneiras de conhecer seus leitores e o universo em que se encontram para poder atingir os objetivos da mediação.

Deve-se salientar que o termo 'leitor' é aqui apresentado em seu conceito lato, ou seja, não restrito apenas à relação do sujeito com o texto escrito, mas entendendo-o também em suas relações com a imagem fixa e em movimento, e com o som. A leitura é a única forma de apropriação da informação, embora ocorra de maneira consciente e inconsciente.

A Figura 1, representa o ciclo de vida da informação nos espaços informacionais sob a ótica da mediação, perpassando-se pelo armazenamento e organização no âmbito implícito, e pela disseminação e o contato direto ao leitor no âmbito explícito. O leitor não é um mero receptor, como normalmente é apresentado no modelo tradicional de comunicação, com base em uma concepção matemática da informação, ao contrário, é ele um agente ativo que interfere ou deve interferir, na construção da informação que irá ou não se apropriar.

Evidencia-se, ainda, que o fator leitor impacta em todas as fases, mesmo que apareça apenas no fim da representação do ciclo na Figura 1, demonstrando a retroalimentação do processo complexo e infindo. A diferença entre a mediação implícita e a mediação explícita pode ser mais bem compreendida, a partir dos momentos em que são deflagradas, sendo a primeira focada no armazenamento e na organização, e a segunda na disseminação e no contato direto com o leitor.

Almeida Júnior (2015, p. 25, grifo nosso) apresenta o conceito de mediação da informação como:

Toda ação de interferência - realizada em um processo, por um profissional da informação e na ambiência de equipamentos informacionais -, direta ou indireta; consciente ou inconsciente; singular ou plural; individual ou coletiva; visando a apropriação de informação que satisfaça, parcialmente e de maneira momentânea, uma necessidade informacional, gerando conflitos e novas necessidades informacionais.

$\mathrm{O}$ ato de mediar se constitui em atividades realizadas por profissionais da informação capacitados para essa ação, cujo processo depende de competências, habilidades e ferramentas adequadas para agir em um sistema complexo (por ser dependente da posição do leitor e de seu contexto), e ininterrupto (pois o mediador medeia a 
informação, não visando ocasionar respostas, mas novas dúvidas, gerando novas necessidades informacionais e, assim, novas mediações).

Um ambiente mediador caracteriza-se pelo trabalho realizado entre mediação implícita e explícita, ou seja, ambas se complementam a partir do momento em que são usadas conscientemente, desde o planejamento e estruturação, até os serviços e atividades executadas. O uso inconsciente da mediação é possível, porém torna ineficaz sua aplicação ampla e direcionada, pela própria deficiência de seu desconhecimento.

A mediação da informação traz em seu cerne a apropriação da informação, tendo o mediador como terceiro elemento [em uma postura atuante, não neutra], e num diálogo construtivo, não excludente ou estático, entre emissor/receptor, livro/leitor e/ou mundo/sujeito. Nessa perspectiva, a subseção seguinte aborda as nuances da apropriação da informação.

\subsection{Apropriação da informação}

No mundo contemporâneo a informação tem se configurado em uma posição de centralidade, servindo de base para que os segmentos da sociedade se organizem e possam definir as estratégias de ação. Informação muitas vezes se transforma em sinônimo de poder. A categorização da informação enquanto 'bem desejável' e cada vez mais adquirível [tanto no âmbito individual, quanto no coletivo], traz o acesso à informação para o status de 'indispensável' em todos os segmentos, se mostrando um forte impulsionador para o desenvolvimento da cidadania, de produção cultural e artística e de processos de inclusão social (RAMOS, 1984).

A informação e o conhecimento passam a ser caracterizados como riquezas, denominados de 'capital intelectual'. As organizações passam a reconhecer a importância desse capital e, assim, enfocam cada vez mais a questão do compartilhamento informacional (BONMANN e BENÍTEZ, 2001). Mas o que é informação? O termo informação pode ser compreendido sob diferentes enfoques e contextos, e pode ser descrito a partir das seguintes definições:

1.1 Registro de um conhecimento que pode ser necessário a uma decisão. [...] 1.2 Informação, na sua definição mais ampla, é uma prova que sustenta ou apoia um fato. 1.3 Registro de um conhecimento para utilização posterior. [...] 2. Com a informação podem-se realizar diversas operações, tais como: criação, transmissão, armazenamento, recuperação, recepção, cópia (em diferentes formas), processamento e destruição. 3. Coleção de símbolos que possuem significados. [...] 5. A informação pode ser descrita em termos do seu objeto de referência, seu significado e estrutura [...] (CUNHA e CAVALCANTI, 2008, p. 201).

A informação, portanto, necessita apresentar-se de modo compreensível, passível de comunicação e independente de materialidade. Conjuntamente a informação, se destacam os conceitos de dado e conhecimento, formando um tríplice pilar no qual dados são fragmentados e possuem uma estrutura simples e, por isso, podem ser facilmente capturados, comunicados e armazenados; informação exige propósito, relevância e análise; e conhecimento é o que se constrói a partir da apropriação de informações para um contexto (DAVENPORT e PRUSAK, 1998a, p. 18).

\begin{tabular}{|c|c|c|}
\hline DADOS & INFORMAÇÃO & CONHECIMENTO \\
\hline $\begin{array}{c}\text { Simples observações } \\
\text { sobre o estado do } \\
\text { mundo }\end{array}$ & $\begin{array}{l}\text { Dados dotados de } \\
\text { relevância e propósito }\end{array}$ & $\begin{array}{l}\text { Informação valiosa da } \\
\text { mente humana. Inclui } \\
\text { reflexão, síntese, contexto }\end{array}$ \\
\hline - Facilmente estruturado & - Requer unidade de análise & - De difícil estruturação \\
\hline $\begin{array}{l}\text { Facilmente obtido por } \\
\text { máquinas }\end{array}$ & $\begin{array}{l}\text { - Exige consenso em relação } \\
\text { ao significado }\end{array}$ & $\begin{array}{l}\text { De dificil captura em } \\
\text { máquinas }\end{array}$ \\
\hline $\begin{array}{l}\text { - Frequentemente } \\
\text { quantificado } \\
\text { - Facilmente transferível }\end{array}$ & $\begin{array}{l}\text { - Exige necessariamente a } \\
\text { mediação humana }\end{array}$ & $\begin{array}{l}\text { - Frequentemente tácito } \\
\text { - De dificil transferência }\end{array}$ \\
\hline
\end{tabular}

Figura 2. Dados, informação e conhecimento - Davenport e Prusak (1998a, p. 18) 
As inter-relações estabelecidas entre os três termos são dinâmicas. A informação se constrói em seu ciclo de vida. Ela é explicitada pelo sujeito produtor inicial, com significados, e recebe interferências e significados em todo o seu ciclo de vida, incluindo os do sujeito leitor, do sujeito apropriador, cujo processo pressupõe mudanças e alterações. O termo apropriar-se, por sua vez, pressupõe o tomar para si, não necessariamente no sentido material. Assim, em um contexto informacional, apropriar-se de uma informação traz em seu âmago a escolha de uma informação como algo passível de significação, de importância, a ponto de ser considerado ou utilizado para algo. Barreto (1994) explora os benefícios da apropriação da informação ao destacar que, quando a informação é apropriada, pode gerar novos conhecimentos e, portanto, modificar o 'estoque informacional' de um indivíduo.

Almeida Júnior (2007, p. 36) ressalta: “A apropriação da informação, que fique claro, pressupõe uma alteração, uma transformação, uma modificação do conhecimento, sendo assim uma ação de produção e não meramente de consumo". Nessa perspectiva, no 'tomar para si' - no âmbito da apropriação - é imprescindível que exista a posição ativa do sujeito que se apropria de algo. Não existe transferência, porque não existe sujeito passivo - o sujeito assume uma posição analítica e crítica. Assim, a informação se constrói a partir da interferência de todos os sujeitos envolvidos no processo de mediação da informação.

Segundo Guaraldo (2013, p. 202), a apropriação da informação "[...] ocorre em diferentes graus, pode ser consciente ou inconsciente, demandar esforço ou não, e [...] resulta na incorporação da informação à vida do leitor, expressando diversas maneiras de ler". A apropriação da informação se refere a uma atividade cognitiva realizada pelo sujeito cognoscente que, ao estabelecer inter-relações com o meio no qual está inserido, gera uma dinâmica que contempla o explícito e o tácito. Tal atividade possibilita que, ao sujeito atribuir significado à informação, a transforma em conhecimento e, assim, pode aplicá-lo em uma decisão ou ação.

\section{A aplicabilidade da Teoria dos Jogos a partir da mediação da informação}

Analisar a inter-relação entre a Teoria dos Jogos e a mediação da informação, no intuito de verificar a aplicabilidade desta interação para a apropriação da informação e a construção de conhecimento é objeto de discussão desta seção.

A proposta dessa inter-relação se pauta na preocupação da mediação da informação com a interferência dos sujeitos no ato da apropriação da informação, fator que sob a ótica Teoria dos Jogos é positivo, uma vez que ela visa transformar uma realidade conflituosa em uma realidade colaborativa, em que as partes - jogadores - se sintam à vontade para negociar e tomarem decisões assertivas.

Essa teoria, conforme mencionando anteriormente, procura analisar as situações de conflito e de cooperação entre jogadores que dependem do comportamento e de ações estratégicas desempenhadas por outros jogadores, no qual o resultado esperado depende da união das partes. Nessa perspectiva, ela evidencia que os próprios jogadores se constituem como principal elemento modificador de sua realidade, uma vez que se apropriaram de informações que julgaram pertinentes ao longo da sua trajetória.

O que se evidencia é que não basta cada jogador se apropriar de informações e agir de maneira individual, pois, se assim o fizer, estará comprometendo suas ações e decisões. Nesse contexto, ressalta-se que nenhum jogador vive isolado, ao contrário, é por meio das interações estratégicas de cooperação entre os jogadores, que se consegue tomar decisões mais precisas e eficazes. Dessa maneira, quando os jogadores selecionam e compartilham informação entre si, objetivam proporcionar uma alteração no conhecimento que possuem, ou seja, realizam a mediação. Nota-se, também, que a ideia de interferência apresentada pela mediação se faz presente.

A mediação da informação busca a apropriação da informação, isto é, se molda na possibilidade de poder propiciar que o jogador possa se apropriar e combinar a informação mediada, conferindo-lhe significado para satisfazer uma determinada necessidade informacional que culminará não no fim de sua busca, mas na ampliação de oportunidades e/ou de novos questionamentos. A informação quando apropriada pelos jogadores, pode impulsionar a construção de conhecimento, modificando o estoque informacional dos jogadores e os beneficiar. Barreto (2009) descreve acerca disso que, 
de entendimento e de saber acumulado; esta apropriação representa um conjunto de atos voluntários, pelo qual o indivíduo reelabora o seu mundo modificando seu universo de conteúdos simbólicos.

Vale lembrar que o indivíduo, também, pode ter seu universo de conteúdos simbólicos reelaborados a partir de atos involuntários, a partir de ações inconscientes. Assim, pode-se afirmar que quando dois jogadores, cada qual com seus 'estoques' de informação e conhecimento, os compartilham entre si, estabelecem inter-relações a fim de maximizar os resultados, por meio das sinergias estabelecidas. A mediação pode ocorrer desde o momento em que o jogador [na postura de mediador da informação] identifica, seleciona, interpreta, organiza e dissemina a informação, propiciando a transformação e/ou modificação no estoque de conhecimento dos outros jogadores. Evidencia-se com isso, que a inter-relação entre distintos jogadores pode contribuir para a construção de novos conhecimentos.

A mediação ocorre, portanto, de forma implícita ou explícita. Implícita no processo de seleção da informação a ser compartilhada, e explícita no contato direto entre jogadores.

Questiona-se: como propiciar a apropriação da informação por parte de outro? Um indivíduo se apropria de algo quando isso the traduz algum significado pertinente, portanto, apropriação pressupõe a agregação de valores individuais. Porém, os valores individuais não são construídos individualmente, ao contrário, é extremamente influenciável pelo sistema histórico-social em que os sujeitos estão inseridos. Em outras palavras, o contexto e o tempo são fatores que impactam na valorização de uma informação e, portanto, são determinantes para a mediação da informação.

Uma organização, seja qual for seu segmento de atuação, não está isolada - sua estrutura e seus profissionais são constantemente influenciados pelo meio/contexto e tempo: questões políticas, econômicas e sociais, tanto no que tange a seu espaço micro [bairro/cidade], quanto macro [estado/país/continente/mundo] trazendo 'pistas' sobre as possíveis necessidades informacionais. Assim, quando a coopetição exercida entre as organizações se pauta numa perspectiva mediadora e não apenas 'disponibilizadora', os jogadores percebem a complexidade do ambiente e visualizam os possíveis cenários que, por sua vez, impactam na construção de uma visão ampliada.

\section{Considerações finais}

A mediação pode não apenas ser utilizada em conjunto à Teoria dos Jogos, mas também pode contribuir significativamente para que esta ocorra de maneira plena e proveitosa para as partes envolvidas.

Aplicando-se a Teoria dos Jogos por meio de uma postura mediadora, a apropriação da informação entre os jogadores ocorre de maneira dinâmica, isto é, os jogadores ao cooperarem entre si propiciam mais informação a ser compartilhada e, ao mesmo tempo, continuam a competir entre si.

A coopetição, um dos elementos tratados pela Teoria dos Jogos, maximiza os resultados dos jogadores, tanto em nível individual, quanto em nível coletivo. A apropriação da informação só é possível se aliada ao compartilhamento de informações de forma mediada - consciente e direcionada.

Para demonstrar o compartilhamento de informações em dois distintos cenários, duas figuras são apresentadas e comentadas a seguir: a Teoria dos Jogos sem Mediação (Figura 3) e Teoria dos Jogos com Mediação (Figura 4). 


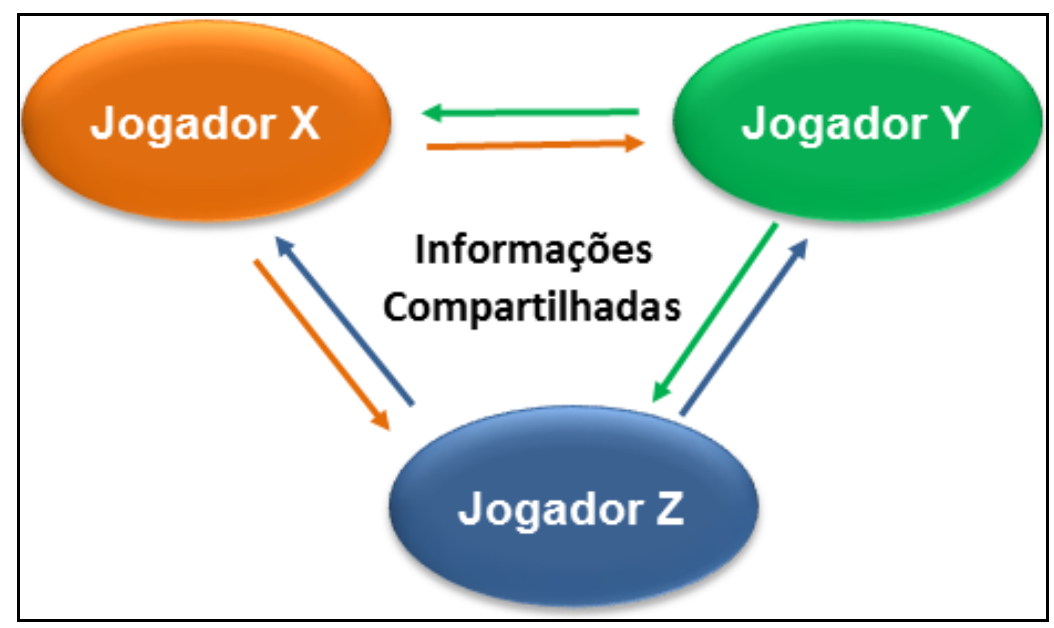

Figura 3. Compartillhamento de informações na Teoria dos Jogos - Elaboração Própria

No contexto da Teoria dos Jogos, ao compartilhar informações visa-se a coopetição, ou seja, compartilha-se informações em troca de receber outras, para que todos os jogadores envolvidos no compartilhamento possam filtrá-las e determinar o que e como usá-las da maneira mais adequada à obtenção de competitividade. Os jogadores são seres estrategicamente treinados para compartilhar as informações adequadas ao seu contexto.

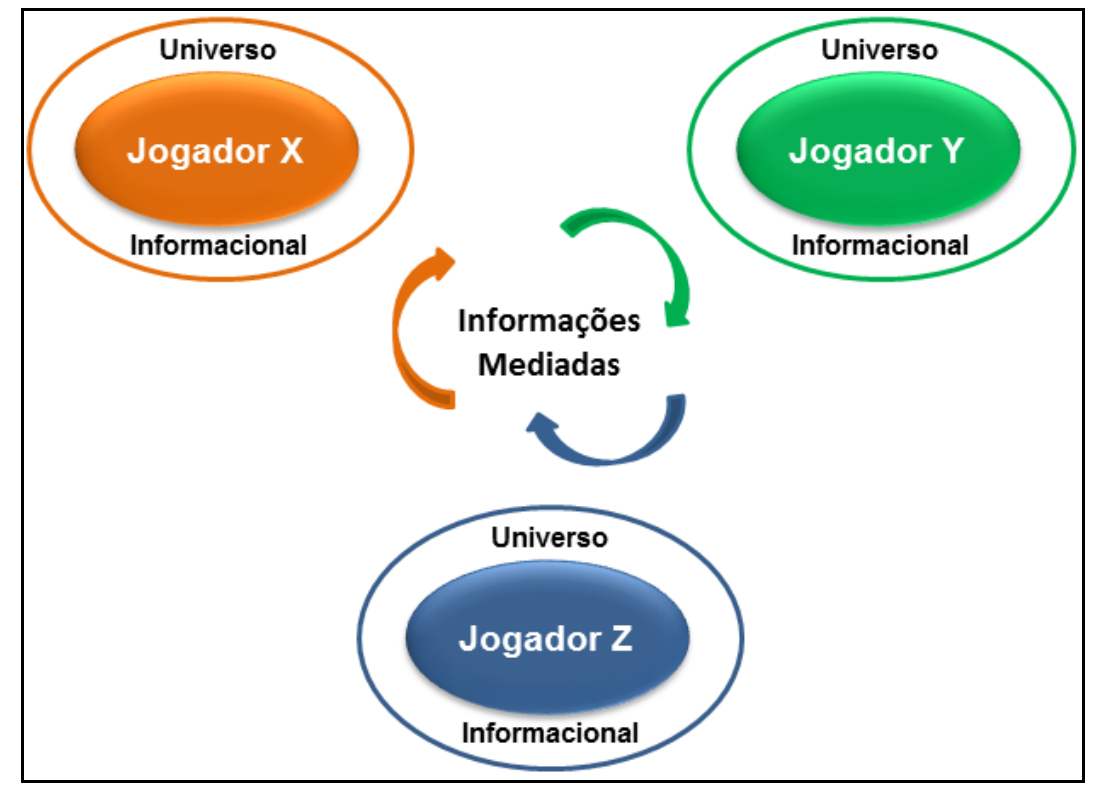

Figura 4. Mediação da informação na Teoria dos Jogos - Elaboração Própria

Ao se adicionar a mediação nesse contexto 'coopetitivo' é possível observar uma maior sinergia no fluxo informacional, que se torna mais organizado e receptivo, bem como a inclusão do aspecto 'universo informacional' acompanhando cada jogador - evidenciando que as realidades dos jogadores são levadas em conta no processo, pois deixam de ser vistos de modo generalizado, buscando-se a dinâmica do compartilhamento.

Quando os indivíduos assumirem uma postura mediadora junto aos demais jogadores, garantirão um ciclo de resposta com a mesma responsabilidade e interesse devido ao trabalho mútuo de mediação aplicado nas informações antes do compartilhamento e, portanto, espera-se que cada jogador possa apropriar-se de mais informação e assim ampliar seu conhecimento e sua vantagem competitiva, o que lhes pode permitir agir com mais precisão e inteligência. 


\section{Referências}

ALMEIDA JÚNIOR, O. F. de. Mediação da informação. 2013. [Slides da disciplina Mediação da Informação, ministrada no programa de Pós-Graduação em Ciência da Informação Unesp de Marília].

Mediação da informação: um conceito atualizado. In: BORTOLIN, S.; SANTOS NETOS, J. A. (Org.). Mediação oral da informação e da leitura. Londrina: ABECIN, 2015. p. 9-32.

Leitura, mediação e apropriação da informação. In: SANTOS, J. P. dos (Org.). A leitura como prática pedagógica na formação do profissional da informação. Rio de Janeiro: Biblioteca Nacional, 2007. p. 33-45.

Mediação da informação e múltiplas linguagens. Tendências da Pesquisa Brasileira em Ciência da Informação, v.2 n.1, [não paginado], jan./dez. 2009

ANGELONI, M. T.; GROTTO, D. A influência na cultura organizacional no compartilhamento do conhecimento. Faces: Revista de Administração, Belo Horizonte, v. 8, n. 2, p. 76-93, abr./jun. 2009.

BARRETO, A. de A. Mediações digitais. DataGramaZero, Rio de Janeiro, v. 10, n. 4, ago. 2009.

BARRETO, A. de A. A questão da informação. São Paulo em Perspectiva, São Paulo, v. 8, n. 4, p. 3-8, out./dez. 1994.

BONMANN, R. D.; BENÍTEZ, Z. R. A importância das relações dialógicas no compartilhamento do conhecimento organizacional. In: WORKSHOP BRASILEIRO DE INTELIGÊNCIA COMPETITIVA E GESTÃO DO CONHECIMENTO \& GESTÃO DO CONHECIMENTO E DA TECNOLOGIA, 10., 2001, Florianópolis. Anais eletrônicos... Disponível em: <https://www.yumpu.com/pt/document/view/39727696/a-importancia-das-relacoes-dialogicas-no-fiesc>. Acesso em: 12 fev. 2016

BORTOLIN, S. Mediação oral da literatura: a voz do bibliotecário lendo ou narrando. 2010. 233f. Tese (Doutorado em Ciência da Informação) - Universidade Estadual Paulista (Unesp), Marília, 2010. Disponível em: <http://hdl.handle.net/11449/103349>. Acesso em: 12 fev. 2016.

CASAROTTO FILHO, N.; PIRES, L. H. Redes de pequenas e médias empresas e desenvolvimento local: estratégias para a conquista da competitividade global com base na experiência italiana. 2. ed. São Paulo: Atlas, 2001.

CONTRACTOR, F. J.; LORANGE, P. Why should firms cooperate? The strategy and economics basis for cooperative ventures. In: CONTRACTOR, F. J.; LORANGE, P. (Orgs.). Cooperative strategies in international business. Lanham (MD): Lexington Books, 2002. 544p.

COSTA, E. A. da; BOTTURA, C. P. A matriz de jogos estratégicos (MJE) como uma nova ferramenta para gestão estratégica via teoria dos jogos. Sistemas \& Gestão, Rio de Janeiro, v. 1, n. 1, p. 17-41, jan./abr. 2006

CUNHA, M. B. da; CAVALCANTI, C. R. de O. Dicionário de Biblioteconomia e Arquivologia. Brasília: Briquet de Lemos, 2008. $451 \mathrm{p}$.

DAVENPORT, T. H.; PRUSAK, L. Ecologia da informação: por que só a tecnologia não basta para o sucesso na era da informação. São Paulo: Futura, 1998a. 316p.

DAVENPORT, T. H.; PRUSAK, L. Working knowledge: How organizations manage what they know. Boston: Harvard Business School Press, 1998b.

DYER, J. H.; NOBEOKA, K. Creating and managing a high performance knowledge sharing network: The Toyota case. Strategic Management Journal, Sussex, v. 21, n. 3, p. 345-367, Mar. 2000

FIANI, R. Teoria dos jogos: com aplicação em economia, administração e ciências sociais. 2.ed. São Paulo: Campus, 2006. $388 p$.

GUARALDO, T. de S. B. Práticas de informação e leitura: mediação e apropriação da informação nas cartas de leitores de um jornal popular do interior de São Paulo. 2013. Tese (Doutorado em Ciência da Informação) - Universidade Estadual Paulista (Unesp), Marília, 2013

HALBWACHS, M. A memória coletiva. São Paulo: Revista dos Tribunais, 1990.

IPE, M. Knowledge sharing in organizations: A conceptual framework. Human Resource Development Review, v. 2, n. 4, p. 337-359, Dec. 2003.

LACOMBE, F.; HEILBORN, G. Princípios e tendências. 2.ed. São Paulo: Saraiva, 2008.

MAIA, M. A. Q. et al. O bibliotecário como mediador no processo de transferência da informação para pessoas com deficiência visual. In: CONGRESSO BRASILEIRO DE BIBLIOTECONOMIA, DOCUMENTAÇÃO E CIÊNCIA DA INFORMAÇÃO (CBBD), 24., 2011. Anais eletrônicos... Maceió: FEBAB, 2011. 
MORIN, E. Introdução ao pensamento complexo. 3. ed. Porto Alegre: Sulina, 2007.

NALEBUFF, B. J.; BRANDENBURGER, A. M. Co-opetição. Rio de Janeiro: Rocco, 1996.

PEREIRA, M. J. L. B.; FONSECA, J. G. M. Faces da decisão: abordagem sistêmica do processo decisório. Rio de Janeiro: LTC, 2009.

RAMOS, A. G. Modelos de homem e teoria administrativa. Revista de Administração Pública, Rio de Janeiro, v. 18, n. 2, p. 312, abr./jun. 1984.

SAUAIA, A. C. A.; KALLÁS, D. O dilema cooperação-competição em mercados concorrenciais: o conflito do oligopólio tratado em um jogo de empresas. Revista de Administração Contemporânea, Curitiba, v. 11, n. especial, p. 77-101, 2007.

SPENGLER, F. M. Mediação: um retrospectivo histórico, conceitual e teórico. In: SPENGLER, F. M.; SPENGLER NETO, T. (Orgs.). Mediação enquanto política pública: a teoria, a prática e o projeto de lei. Santa Cruz do Sul: EDUNISC, 2010. p. $17-57$.

STENMARK, D. Leveraging tacit organizational knowledge. Journal of Management Information Systems, Armonk, v. 17, n. 3, p. 9-24, Winter 2000-2001.

VALENTIM, M. L. P. Cultura organizacional e gestão do conhecimento. Londrina: InfoHome, 2003. 2p. Disponível em: <http://www. ofaj.com.br/colunas conteudo print.php?Cod=70>. Acesso em: 12 fev. 2016.

VITORINO FILHO, V. A.; SACOMANO NETO, M.; SPERS, E. E. Escolas do pensamento estratégico: uma contribuição a partir da Teoria dos Jogos. Internext: Revista Eletrônica de Negócios Internacionais da ESPN, São Paulo, v. 4, n. 2, p. 19-31, jul./dez. 2009.

WINCKLER; N. C.; MOLINARI, G. T. Competição, colaboração, cooperação e coopetição: revendo os conceitos em estratégias interorganizacionais. Revista ADMPG Gestão Estratégica, v. 4, n. 1, p. 1-12, 2011.

ZAMPESE, E. R. de S.; ZILBER, M. A. Estudo de caso de coopetição no compartilhamento de infraestrutura entre operadoras de telecomunicações no Brasil. In: SIMPÓSIO DE ADMINISTRAÇÃO DA PRODUÇÃO, LOGÍSTICA E OPERAÇÕES INTERNACIONAIS. Anais eletrônicos... São Paulo: SIMPOI, 2011. Disponível em:

<http://www.simpoi.fgvsp.br/arquivo/2011/artigos/E2011 T00012 PCN69912.pdf>. Acesso em: 12 fev. 2016. 


\section{Dados dos autores}

\section{Heloá Cristina Camargo de Oliveira}

Doutoranda em Ciência da Informação pela Universidade Estadual Paulista "Júlio de Mesquita Filho" (Unesp) e em Formación en la Sociedad del Conocimiento pela Universidad de Salamanca - Espanha.

heloaoliveira.biblio@gmail.com

\section{Juliete Susan Ferreira de Souza}

Mestre em Ciência da Informação pela Universidade Estadual Paulista "Júlio de Mesquita Filho" (Unesp). Coordenadora do Sistema de Bibliotecas da Universidade Metodista de Piracicaba (UNIMEP).

jubsusann@gmail.com

\section{Marta Lígia Pomim Valentim}

Doutora em Ciências da Comunicação pela Universidade de São Paulo (USP). Professora Titular da Universidade Estadual Paulista "Júlio de Mesquita Filho" (Unesp).

valentim@valentim.pro.br

\section{Oswaldo Francisco de Almeida Júnior}

Doutor em Ciências da Comunicação pela USP. Professor Associado da Universidade Estadual de Londrina; Professor permanente do Programa de Pós-Graduação em Ciência da Informação da Universidade Estadual Paulista "Júlio de Mesquita Filho" (Unesp).

ofaj@ofaj.com.br

Recebido - Received: 2017-01-03

Aceitado - Accepted: 2018-12-11

\section{(cc) EY}

This work is licensed under a Creative Commons Attribution 4.0

United States License.

\section{ULIS D-gate}

This journal is published by the University Library System of the University of Pittsburgh as part of its D-Scribe Digital Publishing Program and is cosponsored by the University of Pittsburgh Press. 